\title{
Ruumi tajumisest, selle keelelis- kultuurilisest kodeerimisest ja representatsiooni poeetikast Desmond Hogani novellis "Viimane kord"
}

\author{
ÜLAR PLOOM
}

Artikkel on ajendatud soovist uurida ruumi kogemist ja selle representatsiooni üldisemalt, käsitledes seda siiski ühe kunstilise teksti raames. Valisin uurimise objektiks iiri autori Desmond Hogani (snd 1950) novelli „Viimane kord” („The Last Time”). Tekst valmistas Tõlkijate Liidu 2017. aastal korraldatud tõlkevõistlusel osalejatele minajutustaja ruumitaju ja representeerimise poeetika iseärasuste tõttu suuri raskusi, kusjuures eriliseks takistuseks adekvaatse tõlke saamisel kujunesid ruumitaju kultuurilise kodeerimisega seotud probleemid.

Käsitlen Hogani tegelase individuaalset ja sotsiokultuurilist ruumirepresentatsiooni põhiliselt Maurice Merleau-Ponty (2019 [1945]) fenomenoloogilise ruumitaju, Henri Lefebvre'i sotsiaalse ruumirepresentatsiooni (1991 [1974]) ja Umberto Eco kultuuriliste erikodeeringute (1979, 2008 [1975]) raames. Artikli eesmärk on Hogani novelli põhjal uurida, kuivõrd on ruumi tajumine individuaalne, kuivõrd individuaalne ruumitaju seondub ruumi sotsiaalse tajumisega ja kuivõrd on ruumirepresentatsioonid seotud inimese keelelis-kultuuriliste harjumustega. ${ }^{2}$ Ehkki uurimus ei keskendu otseselt novelli tõlkimisele ning piirdub eelkõige tõlkeprotsessi analüütilise faasiga, mis seisneb muu hulgas teksti dominandi või dominantide väljaselgitamises, nagu soovitab Peeter Torop (1995), toon ruumitaju kultuurilisi kodeeringuid analüüsides näiteid muudatustest omaenda varasema tõlkega võrreldes. ${ }^{3}$

\section{Novelli sisu kokkuvõte ja analüüsi fookus}

Novelli lühikokkuvõte on järgmine:

Maria, prostituudi orvuks jäänud tütar, kasvab üles Lääne-Iirimaa väikelinna Ballinasloe nunnakloostris Teise maailmasõja järgsel perioodil. Ta kohtab Jamesyt, sama linna jõukast arstiperest pärit taibukat noormeest. Nad on teineteist juba varem märganud, enne kui kohtuvad linnakese laadaplatsil. Noored on teineteisest

\footnotetext{
${ }^{1}$ See ilmus esmalt kogumikus „Teemandid mere põhjas ja muid jutte” („The Diamonds at the Bottom of the Sea and Other Stories”, 1979). Artiklis toetun väljaandele Hogan 2013.

${ }^{2}$ Hogani teksti pole mulle teadaolevalt ei ruumipoeetika ega ka kultuurilise kodeerimise aspektist analüüsitud. Olen varem avaldanud Dante Alighieri „Paradiisi” kolmekümnenda laulu ja Hogani novelli ideaalse ruumi võrdleva käsitluse (Ploom 2019).

${ }^{3}$ Tõlkisin mainitud tõlkevõistluse žürii liikmena teksti ka ise eesti keelde (trükis avaldamata) ning kasutan seda tõlget algupärandi tsitaatide mõistmise hõlbustamiseks.
} 
kohe huvitatud: nad vaatavad koos päikeseloojanguid, istuvad murul või jõeäärsel pingil. Jamesy hakkab Mariale raamatuid laenutama ja teda ka muul moel harima. Ometi lahutavad noori armastajaid erinev sotsiaalne taust ja ajastu kombed. Nii jääbki nende suhe poolikuks, sest Maria tööandja tabab nad kinosaalis teineteise kaisust ning järgmisel päeval saadetakse Maria kloostrist naaberlinna tööle, Jamesy aga suundub isa õhutusel Dublinisse stomatoloogiat õppima. Nad kohtuvad viimast korda Ballinasloe raudteejaamas 1953. aastal, kui Jamesy ei näi Mariat märkavat (nii arvab Maria, kelle vaatepunktist on jutustus esitatud). Maria kolib Iirimaalt Londonisse, abiellub ja kasvatab lapsi. Kakskümmend aastat hiljem, Londonis ja mujalgi maailmas käivitunud tuumapommivastaste meeleavalduste ja protestimarsside ajel, üritab Maria kunagist armastuse ruumi taasluua ja mõista.

Novelli minategelane Maria üritab meenutada ja taasesitada oma noorusarmastuse ruumi tajumusi, mille representatsioonis on oluline osa sotsiaalse ruumi peegeldumisel ja ruumitajude kultuurilistel kodeeringutel. Uurin kõigepealt noore Maria ruumitaju, tema kehaliselt kogetud ruumi avaldumist kirjutava Maria objektiivse(ma)lt orienteeritud ruumi kirjelduste „varjust”. Edasi vaatan, kuidas Maria ruumid liigenduvad sotsiaalses mõttes ja kuidas ta neis ruumides liigub. Kolmandaks selgitan välja, kuidas Maria kodeerib oma reaalse ja ideaalse ruumi sümbioosi kultuuriliselt. Artikli lõpus võtan teksti fenomenoloogiaga seotud tõlkeprobleemid lühidalt kokku. ${ }^{4}$

Maria ruumitajude kogemist ja nende representatsiooni poeetikat suunab tegelikult novelli autor ja seega on tegemist eelkõige ühe novelli ruumipoeetilise analüüsiga. Ometi olen arvamusel, et kõik inimesed meenutavad oma aja- ja ruumikogemusi sarnaselt (jättes kõrvale näiliselt hüpliku teksti kunstilise sujuvuse ja autori kunstilised valikud, mis kindlasti avaldavad oma mõju), st fragmentaarselt ja otsivalt, ühtaegu subjektiivselt, asetudes kunagisse iseendasse kui oma objekti kehaliselt, ja objektiivselt, kui vaatavad seda hoopis teisest kehast ja ruumist uutes kodeeringutes. Nii teeb seda ka Hogani Maria, kes novelli lõpuosas Londonis oma kirjutuslaua tagant aknast välja vaadates mõttes tagasi Iirimaale suundub, et Ballinasloe raudteejaama stseeni (millega novell algab) ja kõike muudki kehaliselt uuesti „mõista” ja läbi elatud armastuse kaotusest ka teadvustatult „aru saada”.

\section{Maria ruumitajust Merleau-Ponty fenomenoloogia taustal ja selle representeerimise poeetikast}

Merleau-Ponty polemiseerib Descartes'iga teadvuse asjus ja asetab „mõtlen, järelikult olen” vastu oma maksiimi „ma suudan[, seetõttu ma olen]” (Merleau-Ponty 2019 [1945]: 226), isegi „ma teen[, seetõttu ma olen]” (Merleau-Ponty 2019 [1945]: 575). „Ma suudan” realiseerib end kehalises ruumis, millest saab kehastatud ruum. Keha ei asetu objektiivselt orienteeritud ruumi (representeeritud ruumi), vaid loob

\footnotetext{
${ }^{4}$ Arvestades eri ruumide integreeritust, luban endale alapeatükkides ristviiteid, samuti tõlgenduslikke ja tõlkelisi ekskursse.
} 
ruumi oma kavatsusliku liikumisega. ${ }^{5}$ (Merleau-Ponty 2019 [1945]: 172, 227, 555614) Keha kavatsuslikkus teostub projitseerumisena objektide poole siin ja praegu, liikumisena siit teatud sealsuse või teisasuse poole (Merleau-Ponty 2019 [1945]: 230, 582). Keha ehitab ruumi tajuaktides, fenomenoloogilises ruumis, ja see kogemus talletub kehasse harjumuslikkusena (Merleau-Ponty 2019 [1945]: 227-241).

Järgnevalt toon lühidalt välja veel mõned Merleau-Ponty kehalise ruumi saamise ja selle teadvustamise liigendused: objektid saavad ilmsiks fenomenaalselt, minu tajuaktide kaudu mingil taustal, mis siiski moodustavad koos ühtse terviku (Merleau-Ponty 2019 [1945]: 227); tähendus pole kunagi täielik, vaid on liikumises algse kavatsuslikkuse (mõtte) poole, mis väljenduses tegelikult iseendast kaugeneb (Merleau-Ponty 2019 [1945]: 584-585). Mina on avatud nii illusioonile kui ka tõele mis tahes objekti puhul: illusioon ja tõde seisnevad tõe võimalikkuses. Tõe võimalikkus tuuakse välja tajuaktiga. Minu keha, mis on lahutamatu maailma nägemisest ja ongi maailma nägemine, mis on tajuaktis kehtima saanud, on kõigi minu väljenduste ja meie omandatud kultuurilise maailmapildi väljendumise võimalus. (Merleau-Ponty 2019 [1945]: 583) ${ }^{6}$ Spontaanne mõte esitub teisiti väljenduses (pildis või kõnes), mis pole „valmis mõtte illustratsioon”, nii et mõtlemise määratlus pole „enesevaldamine, ühtelangevus iseendaga", vaid kõnes mõte nii-öelda ületab iseenda (Merleau-Ponty 2019: 585-586). ${ }^{7}$

Mõtlemises on tähistatu ülemäärasus tähistaja suhtes (Merleau-Ponty 2019 [1945]: 586). ${ }^{8}$ Tähendus on ebatäielik ja nõuab uut väljendust, lõppematut väljendusprotsessi. Nõnda jõuab Merleau-Ponty subjektiivsest kehalisest ehk tajutud ruumist kultuurilise ruumi ehk keeleliselt kontseptualiseeritud ja representeeritud ruumi juurde, kuigi kontseptualiseerimine algab ikkagi kehakogemusest, mis loob projekteeriva, mitte representeeriva teadvuse (Merleau-Ponty 2019 [1945]: 227-229), ja selle harjumuslikkusest. Keha „mõistab” läbi harjumuse omandamise, mis seob teda maailmaga. ${ }^{9}$ Seega toimub liikumine subjektiivse kehatsooni ja objektiivse, univer-

\footnotetext{
${ }^{5}$ Merleau-Ponty viitab seejuures Kanti tõdemusele ruumi loovast liikumisest. Tõlkija Mirjam Lepikult kasutab algteksti termineid intentsionaalne liikumine ja intentsionaalsus, vt MerleauPonty 2019 [1945]: 581-582.

${ }^{6}$ „Meie keha [---] [on] kõigi ekspressiivsete operatsioonide ja kogu kultuurimaailma pärandi võimalikkuse tingimus" (Merleau-Ponty 2019 [1945]: 583).

${ }^{7}$ Merleau-Ponty eristab kõne kavatsuslikkusest johtuvat algupärast ja sekundaarset kõnet: sekundaarses kõnes mõte teiseneb ja ületab iseenda, sest sõnade abil, mille mõte ja tähendus on juba teada, minnakse ikkagi kaugemale algupärasest kõnest, „mis paneb mõtte üldse eksisteerima nii meie endi kui ka teise jaoks". Mõtlemise iseendast eristumise probleemi puutuvalt nendib ta: „Me oleme kutsutud leidma mõtlemise alt, mis naudib enda omandatut ja on ainult peatus lõppematus väljendusprotsessis, mõtlemist, mis püüab end kehtestada ega jõua selleni muidu, kui andes konstitueeritud keele ressurssidele enneolematu kasutusviisi." (Merleau-Ponty 2019 [1945]: 585)

${ }^{8}$ Umberto Eco (1979: 133-136) näitab, et kood tuleb kodeerimisprotsessis sageli alles leida, st algselt on tegemist $\mathrm{n}$-ö toore koodiga, alakodeeringuga, mis võib alles üldiselt heaks kiidetuna kujuneda konventsionaalseks koodiks.

${ }^{9}$ Merleau-Ponty „Taju fenomenoloogia” ingliskeelses väljaandes on leidlik tõlge keha ruumistamiseks harjumuse kaudu: „It [our body] in h a b it s space and time” (Merleau-Ponty 2002 [1945]: 161 [minu sõrendus - $\ddot{U}$. P.]). Mõistmine tähendab kogeda kooskõla selle vahel, mille poole me püüdleme ja mis on meile antud ehk kavatsuslikkuse ja teostuse vahel (Merleau-Ponty
} 
saalse maailma vahel. Merleau-Ponty räägibki kahest ruumist: kogetud kehalisest tsoonist ja orienteeritud ruumist. Esimene on justkui sisu ja teine vorm, aga teisel poleks esimeseta mõtet. Seespoolne, kehaline tsoon on välisruumis varjatult olemas, seda tuleb välise alt otsida. (Merleau-Ponty 2019 [1945]: 174-175)

Hogani novellis on kehaliselt tajuvas ja projekteeruvalt teadvustavas funktsioonis noor Maria ja kontseptualiseerivas, representeerivas funktsioonis kirjutav Maria, kes ühtaegu subjektiveerib ja objektiveerib oma mälestuse ruumi. Võib kohe öelda, et subjektiivne ruum, mille loovad noore Maria kehaline taju ja liikumine, on novellis selgesti hoomatav, ehkki seda tuleb kirjutava Maria representeeritud ruumi alt ikkagi otsida. $^{10}$

The last time I saw him was in Ballinasloe station, 1953, his long figure hugged into a coat too big for him. Autumn was imminent; the sky grey, baleful. A few trees had become grey too; God, my heart ached. The tennis court beyond, silent now, the river close, half-shrouded in fog. And there he was, Jamesy, tired, knotted, the doctor's son who took me out to the pictures once, courted me in the narrow timber seats as horns played in a melodramatic forties film. (Hogan 2013: 7) $)^{11}$

Novelli avalause esimene pool loob objektiivse aja ja ruumi, aga selle alt tuleb kohe esile tajutud sügisene ruum. Ka ruumireaalid ja -tähised on ebamäärased, pigem tajumuslikud ja kehalised kui objektiivruumiliselt orienteeritud: tenniseväljak asetseb „eemal”, jõgi „läheduses” ja Jamesy, kellesse Maria on armunud, seisab „seal”12. Ruumi loomine, nagu ka Jamesy kirjeldus, lähtub tajuvast ja projekteerivalt teadvustavast Mariast. Merleau-Ponty võtmes võib öelda, et subjektiivse ruumi „siin ja praegu" tekib Maria keha kavatsuslikkusest ja situatiivsusest (mitte objektiivsest asetusest ruumis): ehkki kumbki Maria ei liigu Jamesy poole füüsiliselt, teeb seda isegi kirjutav Maria, mäletades kehaliselt noore Maria tajusid ja igatsusi, oma tookordse läheneva mahajäetuse valu; noore Maria liikumist Jamesy poole väljendab eelkõige Jamesy keha „embav” mantel. Ingliskeelne hugged ei ole üksnes poeetiline,

2019 [1945]: 237). Just keha enda kavatsuslikkuses ja selle soorituses avaldub liikumine, situatsioonilisus, millel rajaneb igasugune järgnev tähendus.

${ }^{10}$ Kirjutav Maria asetab enda küll kunagise Maria kehasse ja tajub ruumi koos temaga, aga peab seda tajutud ruumi loo seisukohast siiski mingil määral objektiveerima.

11 'Viimane kord, kui ma teda nägin, oli Ballinasloe raudteejaamas 1953. aastal; tema pikk kogu oli mähitud mantlisse, mis oli tema jaoks liialt suur. Sügis oli ähvardavalt lähedal, taevas hall, hirmuäratav. Ka mõned puud olid halliks tõmbunud. Jumal, mu süda valutas. Tenniseväljak, seal eemal, oli nüüd vaikne, läheduses voolav jõgi pooleldi udulooriga kaetud. Ja korraga oligi seal tema - Jamesy, väsinud, justkui sõlme keeratud, toosama arsti poeg, kes oli mu kunagi kinno viinud ja minuga kitsastel puittoolidel kurameerida püüdnud, kui neljakümnendate melodraamas sarvemuusika mängis.'

${ }^{12}$ Jamesy ja muude asjade „seal olek” on tekstis korduv, mis ei johtu üksnes ingliskeelsele lausele omasest adverbiaalkonstruktsioonist there is / there are: „And there he was, Jamesy [---]”; "There he was that summer, standing on the bridge [---], „There, at a bridge, a central point [---]." Me saame rääkida teatud „sealsuspoeetikast” eelkõige kirjutava Maria aspektist, mis on ühtlasi „siinpraegune" tajuva Maria aspektist. Samal ajal loob there tolle kauguse ja kättesaamatu armastuse „siinsuse”, mis on selle novelli ruumipoeetikas nii oluline. 
vaid toob teravalt esile vaataja taju, milles on füüsilise kontakti mälestus. Mantel ei emba keha ise, vaid teeb seda (nii kogeva kui ka seda mälus taastava) Maria pilgu toimel, tema keha mälestuse ja harjumuse toimel. Kogu ruum on merleauponty'likult öeldes vaid Maria tajuväli: taeva hallus ja ähvardavus, sügiseste puude hallus, uttu otsekui surilina alla maetud jõgi. Kirjutav Maria, kes jutustades representeerib oma armastuse saamislugu ja selle katkemist, rahuldub (Hogani dirigendikepi all) meeleldi just nimelt sellise ruumiga.

Novelli järgnevas lõigus esitatakse Jamesy lühikirjeldus ja mainitakse tema isamaja, mille asupaik on pigem ideaalruumiline - see tõstab esile kirjutava Maria objektiveeriva, lausa geomeetrilise ruumirepresentatsiooni, mille poeetika täpsustub hilisemas tekstis.

His father had a big white house on the perimeter of town - doors and windows painted as fresh as crocuses and lawns gloomy and yet blanched with perpetually new-mown grass. (Hogan 2013: 7) $)^{13}$

Lugeja saab teada, et Jamesy isa maja asub on the perimeter of town 'linna perimeetril, ringjoonel'. Muidugi võiks lihtsalt öelda, et äärelinnas või linna servas. Aga kirjutav Maria ei ütle on the outskirts või muud sarnast. Meie ruumiteadvuses pole esindatud ainult kehaline pool, vaid ka ideaalne, abstraktne pool. ${ }^{14}$ Ideaalse ruumiteadvuse avastame sageli oma igapäevase, harjumusliku ruumitaju representeerimisel. Mida tähendab linna keskus? Kes on seda keskust täpselt mõõtnud? See on geomeetriliselt täpne vaid ideaallinnades, mille kavandasid näiteks renessansi ehitusmeistrid Filarete või Leonardo ja mis sündisid enam-vähem samaaegselt abstraktsete utoopiatega. Samal ajal võime tajuda ka mitteideaalset linna mingi ideaalse keskuse ja perifeeriana, ehkki ei kujuta seda ei ringi ega ruuduna. Ka Hogani novellis jääb ideaalne ruum kusagile subjektiivselt tajuva ja objektiivselt representeeriva teadvuse vahele. Ehkki noor Maria tajub ruumi kehaliselt, kasutab kirjutav Maria kultuuris kindlalt kodeeritud mõistestikku. Tôlkimisel on sellise ruumiga seonduv väljend paras pähkel. Tõlkisin väljendi on the perimeter of town ise esmalt kui „linna servas” (vt tsitaadi tõlget joonealuses), mis tähistab pigem subjektiivset ruumi, aga sel juhul läheb ideaalne ruum kaduma. Võib-olla peaks kaaluma selliseid tõlkevõimalusi nagu „linna välisringil” või isegi, esmasest kummastusest hoolimata, „linna perimeetril”, mis loob pigem geomeetrilise ruumi. ${ }^{15}$ Kokkuvõttes saab meenutava Maria representeerivas teadvuses siiski ilmsiks noore Maria kehaline taju, maja ja selle ümbruse tunne: akende ja uste krookusvärske värv, muru samaaegne süngus ja valevus.

\footnotetext{
${ }_{13}$ 'Tema isal oli linna servas suur valge maja - selle uksed ja aknad olid sellist värvi nagu värsked krookused, muruplatsid aga sünged, ehkki pideva niitmise tõttu päikesest pleekinud.'

${ }^{14}$ Merleau-Ponty (2019 [1945]: 378) järgi kavandab keha ka ideaalse ruumi oma kogemuse põhjal.

${ }^{15}$ Merleau-Ponty (2019 [1945]: 581) järgi on ka geomeetrilises ruumikogemuses tallel kehaline kogemus ja ,geomeetria subjekt on motoorne subjekt”.
} 
Lugu täpsustub novelli edasistes lõikudes - saame teada, et Maria elas kloostri orbudekodus - ning neiski oleme tunnistajaks subjektiivse tajuruumi jälgedele objektiivses representatsioonis.

In my girlhood I observed Jamesy as I walked with nuns and other orphans by his garden. I was an orphan in the local convent, our playfields stretching by the river at the back of elegant houses where we watched the nice children of town, bankers' children, doctors' children, playing. Maria Mulcahy was my name. My mother, I was told in later years, was a Jean Harlow-type prostitute from the local terraces. I, however, had hair of red which I admired in the mirror in the empty, virginal-smelling bathroom of the convent hall where we sat with children of doctors and bankers who had to pay three pence into the convent film show to watch people like Joan Crawford marry in bliss. (Hogan 2013: 7) ${ }^{16}$

Teatav objektiivne ruumirepresentatsioon on loo seisukohast oluline ${ }^{17}$ ja tegemist on kogu novelli ühe objektiivsema lõiguga, aga me ei saa teada, kus ikkagi täpselt on need ridamajad (the local terraces), kust oli pärit Maria prostituudist ema. Ja kloostri siseruumi kirjeldus on seotud selle ruumi tajumisega (virginal-smelling bathroom 'neitsilikult lõhnav pesuruum'). Selles lõigus luuakse sotsiaalne heterotoopia Lefebvre'i ja Foucault' võtmes (vt 3. peatükki). Samuti antakse esimene viide filmides loodud ideaalsete ruumide põimumisele minategelase reaalse ruumiteadvusega (vt 4. peatükki).

Muidugi tuleb Hoganil teatava objektiivsusega esitada ka Maria vastasmängija Jamesy -, aga selgub, et siingi on noore Maria subjektiivsel kehatajul ja selle teadvustamisel oluline osa. Samal ajal selgub sellise objektiivsuse-subjektiivsuse pingeväljas huvitav asi, mis on kunstilises tekstis oluline: lineaarse diskursuse seos kogu teosega, mis eeldab liikumist tekstilt teosele ja tagasi.

Jamesy was my first love, a distant love.

In his garden he'd be cutting hedges or reading books, a face on him like an interested hedgehog. The books were big and solemn-looking - like himself. Books like War and Peace, I later discovered. (Hogan 2013: 7) ${ }^{18}$

\footnotetext{
16 'Kui ma alles tüdruk olin, jälgisin Jamesyt hoolega, kui koos nunnade ja teiste orbudega tema aiast mööda kõndisin. Ma olin vaenelaps kohalikus kloostris; meie mängumaad ulatusid jõe kaldal elegantsete majade taha, kus me linna korralike laste, pankurite ja arstide laste mängimist pealt vaatasime. Maria Mulcahy oli mu nimi. Minu ema, öeldi mulle aastaid hiljem, oli prostituut linna ridamajade rajoonist ja sarnanes välimuselt Jean Harlowga. Minul aga olid hoopiski punased juuksed, mida ma imetlesin tühja neitsilikult lõhnava tualettruumi peeglist kloostri peahoones, kus me istusime koos arstide ja pankurite lastega, kes pidid tasuma kloostri filmiseansile sissepääsuks kolm penni, et näha Joan Crawfordi suguseid naisi õndsalt abiellumas.'

${ }^{17}$ Kindlasti teame palju radikaalsemalt subjektiivsemaid tajumuslikke representatsioone, kui mõelda näiteks Karl Ristikivi „Hingede ööle”.

18 'Jamesy oli minu esimene armastus, kauge armastus. Kui ma teda aias juhtusin nägema, pügas ta hekki või luges raamatuid, näoilme selline nagu uudistaval siilil. Raamatud olid suured ja mõjusid pidulikult nagu ta isegi. Sellised raamatud nagu „Sõda ja rahu”, avastasin ma hiljem.'
} 
Väljendi „kauge armastus” (distant love) võimalik mõte selgub alles teksti lõpuni lugemisel, mis kohustab liikuma terviku ja osade vahel. ${ }^{19}$ Teksti kui teose jätkuvale saamisele, teose mõtte fenomenoloogiale viitab ilmekalt jutustav Maria, kes ütleb viimases lauses: „I touch upon truth” (Hogan 2013: 13). „Ma puudutan tõde” pole ehk päris õige tõlkevaste, ehkki see on tajumuslik. „Ma liigun tõe poole” on mõtteliselt n-ö õigem, aga tajumuslikult kaugem. Ja Jamesy kui distant love - on see „kauge armastus” või „kaugele jääv (jäänud) armastus”? Kauge on siin ühtaegu epiteedina retooriline ja ka kogu teost iseloomustav poeetiline kujund, samuti mõtlemist väljendav kujund. Selles väljendub ruumiline lahusolek, aga ka arusaamatus, „kaugeks” ehk mõistmatuks jäänud ruum. Mitte asjata ei ütle kirjutav Maria ühes teises tekstilõigus: „There'd been something I wanted of Jamesy which I'd never reached” ('Jamesys oli midagi, mida ma olin tahtnud, aga milleni ma polnud kunagi küündinud, Hogan 2013: 11), mis seondub ühtlasi nende armastuse ruumi (mitte)mõistmisega: „[---] and tried to decipher an area of loss, a morning by the station, summer gone" ('[---] ja katsusin mõttes nii ühes kaotuse ruumis kui ka ühes rongijaama suvelõpuhommikus selgust saada, Hogan 2013: 12).

Kunagi kogetud ruumide uus tajumine ja siiski ka nende teatud dešifreerimine, õigemini ümberkodeerimine on Maria tagasivaatelise kirjutamise kinnisidee. Kus oli täpselt see koht, kus Jamesy äkki kaduma läks?

On huvitav, et Hogan laseb ka kontseptualiseeriva-representeeriva ruumi puhul, mis päädib eeltsiteeritud tõdemusega „I touch upon truth”, kasutada tajuruumi tähistavat verbi touch, mistõttu võiks isegi tõlkida „ma puudutan juba tõde”. ${ }^{20}$ Kehalised tajud, mis peegelduvad nii verbides kui ka adjektiivides ja erilistes, individuaalsetes ja objektiivselt mitteorienteerivates kohaviidetes, on kogu novellis silmatorkavalt rohked ja mitmekesised. Vaid mõni näide:

He took my hand.

I leaned against his jumper; it was fawn colour.

I clumsily clung to the fawn and he took me and I was aware of strands of hair, bleached by sun. (Hogan 2013: 9) $)^{21}$

\footnotetext{
${ }^{19}$ Juri Lotman on eristanud retoorika kahel tasandil: avatud teksti retoorika, mis käsitleb tekstiloomet, milles oluline on kujundiretoorika, ja suletud teksti retoorika, mis on teksti kui terviku retoorika (Lotman 1990 [1981]: 218). Olen sellega muidugi nõus, lisaksin vaid, et kujundiretoorika jätkub just nimelt kujundipoeetikana tervikteksti tasandil, liites retoorilise, tekstiloometasandi selle saamise, tekstipoeetika tasandiga.

${ }^{20}$ Novelli ühest lõigust (Hogan 2013: 10) selgub, et just nimelt puudutamine on Maria ja Jamesy vastastikuses „kasvatusruumis” oluline: „[---] Jamesy and I would meet by the river, in the park - briefly, each day, touching a new part of one another. An ankle, a finger, an ear lobe, something as ridiculous as that" ('[---] hakkasime me, Jamesy ja mina, jõe ääres pargis sageli kokku saama, puudutades põgusalt, iga päev, mingit uut kehaosa teineteises. Pahkluud, sõrme, kõrvalesta või midagi muud niisama tobedat').

${ }^{21}$ ’Ta võttis mul käest kinni. // Ma liibusin tema džempri vastu; see oli kollakaspruuni värvi. // Ma klammerdusin sinna kollakaspruuni kinni ja tema võttis mu käte vahele ja ma tundsin oma näol ta päikesest pleegitatud juuksesalke.'
} 
Maria meenutustes kerkib esile just too kehaline, projekteeriv teadvus ja need talle või neile kehaliselt teada olevad ja samal ajal keeleliselt objektiveerimata paigad:

Yet our meetings were just as few and as autumn denuded the last cherry-coloured leaves from a particular house-front on the other side of the town, Jamesy and I would meet by the river [---]. (Hogan 2013: 9-10) ${ }^{22}$

Just see a particular house-front on the other side of the town 'eriline [mulle/meile teadaolev] majaesine linna teises otsas' näitab, kui isiklik ja kehaline on Maria ruum, n-ö objektiivruumiliselt peaaegu tähistamata.

Sääraseid eriliselt isiklikkusele vihjavaid tähistusi leidub novelli kirjeldustes veel. Ometi ei jää kehaline taju ainsaks, pealegi ebamääraseks ruumiliigendajaks. Kehalisele poolele sekundeerivad nii sotsiaalne kui ka kultuuriliselt kodeeritud ruum, mis mõlemad avalduvad Maria sotsiaalses ja kultuurilises teadvuses ning liituvad kehalise tajuruumiga.

\section{Sotsiaalsete ruumide representatsioonist}

Loomulikult lähevad eri ajad ja ruumid kirjutava Maria teadvuses vaheliti. Vaheliti minek algab novelli algul esitatud põgusast hüvastijätumeenutusest, mille kohta lugeja kohe ei mõistagi, et tegemist on hüvastijätuga. Selle juurde jõutakse tekstis ringiga tagasi, kui selgub, et Jamesy ei näi jaamas Mariat märkavat. Rongis sõidavad nad sotsiaalset vahet arvestades eri klassi vagunites ega kohtu enam kunagi.

The mornings were drab and grey. I'd been working a year in Athlone, mind disconnected from body, when I learned Jamesy was studying dentistry in Dublin. There was a world of difference between us, a partition as deep as war and peace. Then one morning I saw him. I had a scarf on and a slight breeze was blowing and it was the aftermath of a sullen summer and he was returning to Dublin. He didn't look behind. He stared - almost at the tracks - like a fisherman at the sea. [---] I travelled on the same train with him as far as Athlone. He went to Dublin. We were in different carriages. (Hogan 2013: 11-12) ${ }^{23}$

\footnotetext{
22 'Siiski olid meie kohtumised harvad; aga kui sügis rebis ühe mulle teada oleva maja eest linna teises servas viimsedki kirsipunased lehed, hakkasime me, Jamesy ja mina, jõe ääres pargis sageli kokku saama [---]'

${ }_{23}^{23}$ 'Hommikud olid ilmetud ja hallid. Ma olin Athlone'is aasta aega töötanud, vaim kehast lahus, kui sain teada, et Jamesy õpib Dublinis hambaarstiks. Meie vahel haigutas terve kuristik, niisama sügav erinevus, kui on sõjal ja rahul. Siis ühel hommikul ma nägin teda. Mul oli sall kaelas ja puhus kerge tuul ja igav suvi oli jõudnud lõppfaasi ning tema pöördus Dublinisse tagasi. Ta ei vaadanud selja taha. Ta vahtis seal - nina peaaegu rööbaste kohal - nagu kalamees merd. [---] Ma sõitsin temaga samas rongis kuni Athlone'ini. Tema sõitis edasi Dublinisse. Me olime eri vagunites.'
} 
Veel fragmentaarsemalt kui füüsilised ruumitajud luuakse Hogani novellis sotsiaalne heterotoopia. ${ }^{24}$ Sotsiaalse ruumi(re)produktsiooni klassiku Henri Lefebvre'i (1991 [1974]: 33 ja passim) mõtteid kokkuvõtvalt esitades võib nentida, et sotsiaalsete suhete teostamisel inimesed (taas)toodavad sotsiaalset ruumi; et iga elav keha on ruum, mis taastoodab end füüsilises ja sotsiaalses ruumis ning mida saab tähistada füüsiliselt või mingis diskursuses märgiliselt (Lefebvre’i näited on piir ja pass); et tajutud sotsiaalne ruum, mis väljendub tajutud sotsiaalsetes praktikates (siia kuuluvad ruumikompetentsus ja ruumiline käitumine), jagab ruumi tsoonideks ja eraldab need (vrd Foucault' heterotoopiatega); et kontseptualiseeritud ruum ${ }^{25}$ moodustub ruumi kontseptualiseerivast ja seda representeerivast ruumilisest teadmisest koos vastavate märkide ja koodidega, mis väljendub näiteks linnaruumi sümboolsetes liigendustes (kirikud, surnuaiad, administratiivalad jne); et linnaruum on aktiivne ruum, mille loovad koostoimeliselt arhitektid, urbanistid, ideoloogid; et konkreetselt „elatud” ruumid koos vastavate kujundite ja sümbolitega on elanike passiivselt kogetud ruum, mida eri kujutluses endale omaseks muudetakse.

Seega võib lihtsustatult öelda, et elatud ruumis ühendub füüsiliselt tajutud ruum kujutletud, sümboolsete ja abstraktsete ruumidega. Noore Maria elatud ja kirjutava Maria representeeritud ruum sisaldab tagasivaatelistes fragmentaarsetes kirjelduses ikka ja jälle sotsiaalset heterotoopiat. Esimeses lõigus saime teada, et Jamesy on arsti poeg, teises seda, et nende maja asukoht on linnakese välisringil, ilmselt jõukas kvartalis. Kolmandas selgub, et kloostrikasvandike ruumiline eraldatus luksusmajadest on veelgi suurem. Selgub ka Maria prostituudist ema päritolu vaesest ridaelamurajoonist. Viimase kohtumise stseenis sõidab kumbki eri klassi vagunis. Maria on töötanud rõivapoes ja hoidnud lapsi, Jamesy on põhiliselt tegelenud enda harimisega raamatute abil. Pärast kinosaalis lahutamist saadetakse Maria tööle naaberlinna Athlone'i, Jamesy aga tudeerib Dublinis. Arhitektide, urbanistide ja ideoloogide linnaruum eraldab ja ühendab raudteejaamades, kirikutes, kloostrites: jaam ja perroonid justkui ühendavad, vagunid klassifitseerivad ja eraldavad; klooster eraldab, aga kloostrikino ühtselt harivad filmid ühendavad, sest sinna tulevad kasvatusliku sisuga filme vaatama ka pankurite ja arstide lapsed. Ka asumiheterotoopiatele vaatamata on linnakeses ühiskonda ühendavaid punkte. Niisugune punkt on näiteks laadaplats, kus noored esmakordselt kohtuvad ja kus mängib (see selgub hilisemas lõigus) sümboolselt vabastav džässmuusika.

\footnotetext{
${ }^{24}$ Heterotoopia mõiste on laialdaselt levinud tänu Michel Foucault' käsitlusele nn heterotopoloogiast, mis hõlmab nii reaalse kui ka kujutlusliku ruumi aspekte: mingeid ruume või ruumitsoone võidakse tajuda ja teadvustada muudena, teistsugustena, teistega kokku sobimatutena ja teistele vastanduvatena või isegi vaenulikena. Foucault' tuntud näited on surnuaed, saun, baar, lõbumaja, aed, vangla jt (vt Foucault 1984 [1967]).

${ }^{25}$ Kasutan mõistet kontseptualiseeritud ruum mõiste mõistetud ruum asemel kooskõlas MerleauPonty eristusega kontseptualiseeritud ruumi kui representeeritud ruumi ja kehaliselt mõistetud tajuruumi vahel.
} 

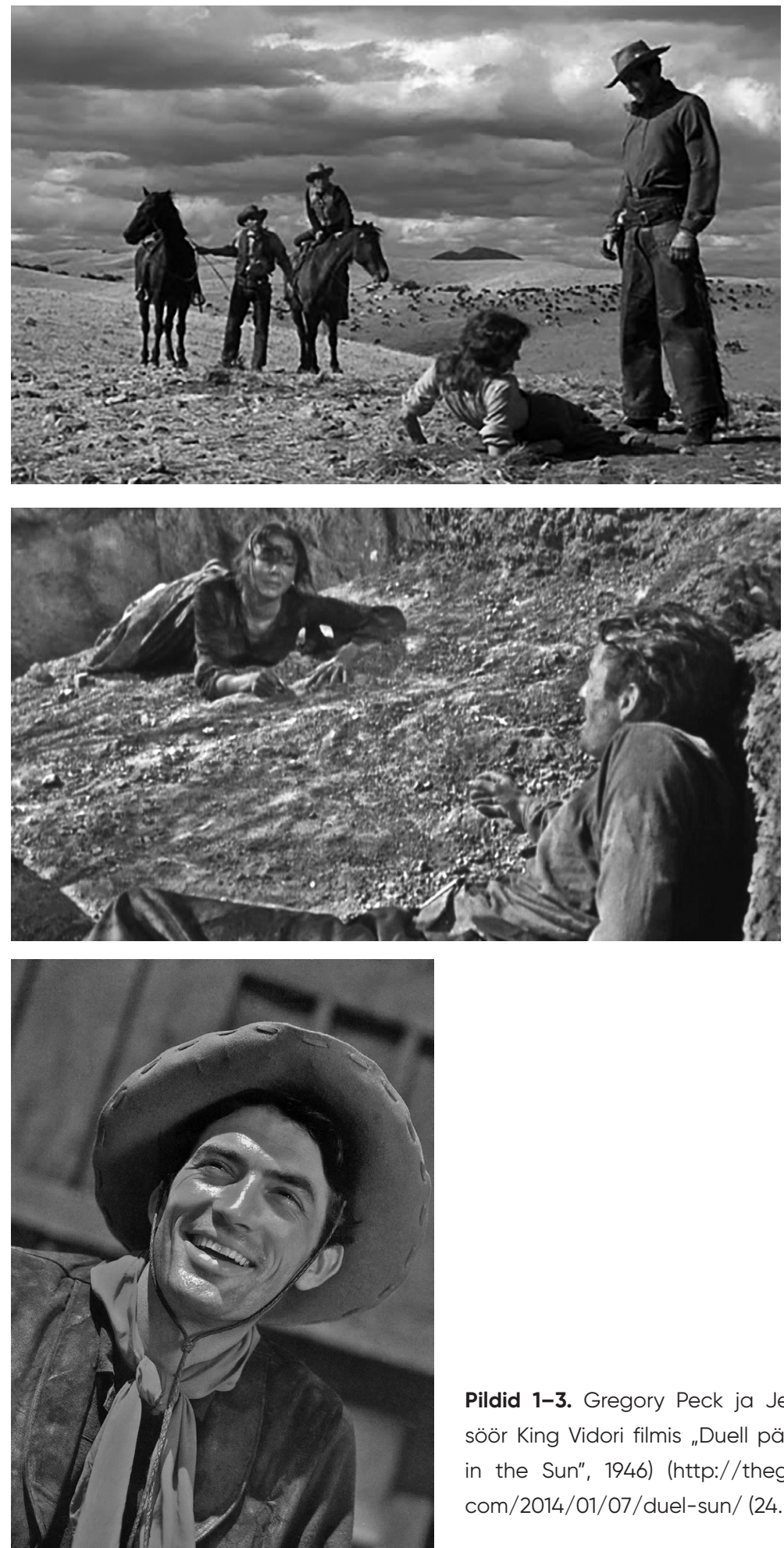

Pildid 1-3. Gregory Peck ja Jennifer Jones režissöör King Vidori filmis „Duell päikesepaistes” („Duel in the Sun", 1946) (http://thegreatwesternmovies. com/2014/01/07/duel-sun/ (24. VIII 2020)) 
Jamesy and I met first in the fair green. I was wheeling a child and in a check shirt he was holding a rabbit. The green was spacious, like a desert. Duel in the Sun was showing in town and the feeling between us was one of summer and space, the grass rich and twisted like an old nun's hair.

He smiled crookedly. (Hogan 2013: 8) ${ }^{26}$

Maria elatud ruum ühendab tajutud füüsilise ruumi, sotsiaalse ruumi ja kultuurilise, sümboolse ruumi. Sotsiaalne eraldatus ilmneb sellest, et kahel noorel on samas ruumis eri ruumipraktikad: Maria tuleb laadaplatsile töökohuseid täites lapsevankriga, „varastades” jõudeaega; Jamesyl on jänese kussutamine siiski pigem meelelahutus. Muidugi esitatakse ruum eelkõige Maria taju ja erilise ruumiteadvuse aspektist. Nimelt põimub Maria konkreetne ruum mingi ideaalse ruumiga, mis väga sageli seondub tema kultuurikogemusega. Enne Jamesylt raamatute laenamist on selleks filmid, mida Maria kloostrikinos näeb. Siiski võib arvata, et väljas tööl käies on ta näinud ka linnakinos linastunud filme või vähemasti afiššide põhjal kujutanud, mis võiks neis juhtuda. Ülaltoodud katkendis tunnetab Maria ruumi populaarse vesterni „Duell päikesepaistes” järgi, mis põimub tema kloostrikogemusega ja mis põhjustab tema ruumitaju erilise teadvustamise: roheline laadaplats on avar nagu vesterni stseenides nähtud (pool)kõrb (vt pilte 1 ja 2) ja samal ajal tundub talle rohi olevat krussis nagu vana nunna juus. Lisaks naeratab Jamesy nagu filmi kurikaelast meespeategelane (crook) (pilt 3). See annab tajuva Maria ruumiteadvusele ja kirjutava Maria ruumirepresentatsioonile erilise topeltkodeeringu.

\section{Maria ruumirepresentatsioonide erikodeeringud}

Kehalisest tajumisest jõuab Maria (nagu iga inimene) paratamatult oma ruumitajude keelelis-kultuurilise väljenduse juurde, mille alt Merleau-Ponty küll soovitas esialgset tajulist mõistmist otsida, aga mis ühtlasi seda mõistmist uuenevalt suunab ja teisendab. Me ikkagi kõneleme oma tajudest ja iseloomustame neid otsivalt sageli mingite võrdluste kaudu, mis on individuaalselt paratamatult seotud meie kasvuja arengukeskkonnaga, selle kultuurilis-keeleliste tavadega. Keelekoodid on ühtlasi kultuurikoodid, nii kultuuris juba kinnistunud koodid kui ka alles kinnistamist otsivad koodivõimalused.

Umberto Eco (2008 [1975]) eristab kultuurikoodide muutlikkusega seotud ülekodeeringuid (hüperkodeeringuid) ja alakodeeringuid (hüpokodeeringuid). Ülekodeerimine reguleerib mingeid suuremaid tekstiüksusi uudsuse ja harjumuslikkuse piiril. Keeles avalduvad uudsus ja harjumuslikkus ilmekalt fraseologismides (nt „kuidas käsi käib?”, „läks vett vedama”), aga ka žanrimarkeritena (nt „elas kord” muinasjutus) või tuntud ikonograafiliste ülekodeeringutena. Topeltkodeering ilm-

\footnotetext{
26 'Jamesy ja mina kohtusime esimest korda linna laadaplatsil. Mina kärutasin vankris last ja temal oli seljas ruuduline särk ning jänes süles. Laadaplats oli avar kui kõrb. Kinos näidati vesternit „Duel in the Sun” ja meie vahelises tundes oli suve ja avarust, rohi ümberringi rikkalik ja krussis nagu vana nunna juus. // Ta naeratas viltuselt.'
} 
neb näiteks kahe fraasi „elasin kord ühe naisega” ja „elas kord üks naine” võrdlemisel, sest teises fraasis tunneme ära žanrilise ülekodeeringu. Erikodeering ${ }^{27}$ avaldub ka pildil, mis kujutab naist kandikuga, millel on silmad. Ajastulist erikoodi teades mõistame, et tegemist on püha Luciaga, kelle silmad välja torgati (Eco 2008 [1975]: 188-189). Kõigis nimetatud näidetes on tegemist keeleliste ja kultuuriliste harjumustega. Uuenduste puhul on esialgu tegemist hoopiski alakodeeringuga, st päris koodi kui sellist veel pole ja kood on alles hüpotees. ${ }^{28}$ Eco järgi liigutakse ülekodeerimise protsessis olemasolevatelt üldkoodidelt analüütiliste allkoodide poole, samas kui alakodeerimisel on suund veel mitte eksisteerivatelt või teadmatutelt koodidelt potentsiaalsete ja üldistavate koodide poole (Eco 2008 [1975]: 191).

Tulles erikodeeringute juurde Hogani novellis, näeme Maria ruumiteadvuses tugevat kultuurilist ülekodeeringut, milles osaleb nii tema kloostrikasvatus ja -kultuur kui ka nähtud filmid nii kloostris kui (arvatavalt) ka linnakese kinos. Maria väljendab oma ruumitaju Jamesyga kohtumisel enda kultuurilise kompetentsi piirides, mõnikord vastavat koodi alles otsides, mõnikord sellele üksnes vihjates, mis seab tõlkija küllaltki keerulise probleemi ette. Kuidas tõlkida näiteks Jamesy naeratuse kohta käivat lauset „He smiled crookedly” eelmises tsitaadis? Lootes vaid lugejate taiplikkusele ja tõlkides „Jamesy naeratas viltuselt”, ei jõua implitsiitne erikodeering ilmselt lugejani.

Hogani novellis (nii nagu eluski) on ruumitajud ja nende representatsioonid sulandunud. Linna kontseptualiseeritud ruum(id) - klooster, tööpaigad, tenniseväljak, laadaplats, jõgi ja jõeäärne park, äärelinna majad aedadega ning muu - põimuvad noore Maria tajumusliku ja kirjutava Maria representeeritud sümboolsete ruumielementide ja kujunditega (mida ta kogeb üksi või koos Jamesyga olles). Need moodustavad erinevalt, sageli vastandlikult tajutud tsoone: suletud kloostriruumile ja tööruumidele naaberlinnas vastanduv jõgi koos pargi ja jõeäärse pingiga on turva-, aga samuti üksilduse ja unistuste paik; kloostri filmisaal ja filmides nähtud-kogetud ruumid aga unistuste ja fantaasiate ruum, millele annavad tuge Jamesylt laenatud raamatud; laadaplatsi (näiliku) vabaduse ja võrdsuse ruum ${ }^{29}$ ning üle jõe viiv sild, mille juures Maria ja Jamesy kohtuvad ning mida kirjutav Maria representeerib kui nende ideaalse armastusruumi sümboolset keset.

Maria kultuuriline kogemus sekkub tema kunagiste kehatajude ja nende teadvustamise representatsiooni. See kindlasti laseb neil nii esile tulla kui ka muudab neid. Maria kultuurilist kogemust mõjutavad põhiliselt kolm eri diskursust, mis on omandatud kloostris ja Jamesy kaudu:

\footnotetext{
${ }^{27}$ Kuna üle- ja alakodeeringutel on sageli raske vahet teha, soovitab Eco üldjuhul kasutada erikodeeringu mõistet (Eco 2008 [1975]: 136).

${ }^{28}$ Eco viitab Charles S. Peirce'i näitele muusikapalast, mida kuulates kuulaja tajub midagi, mida ta ometi ei suuda kodeerida. Eco nimetab seda abduktiivseks operatsiooniks (Eco 2008 [1975]: 190).

${ }^{29}$ Foucault'le tuginedes saab eristada suletud kloostriruumi ja laadaplatsi avatud ruumi.
} 
1) katoliiklik diskursus koos vastavate kujunditega, ${ }^{30}$ mis tuleb näiteks esile novelli algul esitatud jaamastseeni tajumise pärastisel täpsustamisel (dresses I'd resurrected from nowhere 'kleidid, mis olid minult justkui ülestõusmise saanud'31),

2) filmidest nähtu (kloostris ja linnakinos),

3) kirjandusest loetu ja muusikast kuuldu (Glenn Milleri motiiv meenub Mariale laadaplatsi kunagisi tulesid ja värve kirjeldades ikka ja jälle).

Nimetatud diskursustes peenendub ja ilmselt ka teiseneb Maria ruumitaju. Maria kujutab oma suhet Jamesyga peamiselt filmilikult ja katoliiklikult, aga toimub ka ühe valdava kultuurilise ülekodeeringu asendumine teisega. Esmalt domineerib film (protestikood katoliikliku koodi vastu). Peale esmakohtumise ruumitaju ja selle representatsiooni filmiliku ülekodeeringu tuleb seesama kodeering eriti võimsalt esile Maria reaktsioonis Jamesy (arvatavale) soovimatusele teda viimasel kohtumisel märgata. Maria laseb Jamesy sümboolselt maha, nii nagu toimub nais- ja meespeategelase vastastikune mahalaskmine (vt pilti 2) vesternis: „Jamesy Murphy, you're dead', I said - my head reeled. 'Jamesy Murphy, you're dead." (' „Jamesy Murphy, sa oled surnud," ütlesin ma. Mu pea käis ringi. „Jamesy Murphy, sa oled surnud." Hogan 2013: 11).

Pärast hüvastijätuta jäänud kohtumist Ballinasloe jaamas teeb Maria otsuse Iirimaalt lahkuda. Ta kohtab Londonis Iirimaalt pärit ehitusmaaklerit. Nad abielluvad ja saavad lapsed. Jamesy on Maria jaoks (peaaegu) maha maetud. Nüüd kannab Maria selliseid pakse ruudulisi särke, nagu oli olnud seljas Jamesyl, kui nad esmakordselt kohtusid, mis näitab, et vähemalt Maria alateadvuses polnud Jamesy lõplikult surnud. Pealegi sunnib 1960-ndate alguse Londoni kogemus Mariat oma Ballinasloes kogetud armastuse ruumi teistmoodi kodeerima. London on üle ujutatud eri nahavärvi inimestest, sotsiaalne ebavõrdsus avaldub teisiti kui Iirimaal; nagu avatud maailmas mujalgi, leiavad seal aset tuumapommivastased meeleavaldused. Maria mõistab äkki, et ka nemad on Jamesyga olnud mingis mõttes vastupanuliikujad.

[---] but occasionally, wheeling a child into Battersea funfair ${ }^{32}$, I was reminded of Jamesy, a particular strand of hair blowing across his face. Where was he? Where was the hurt and the sensitivity? London was flooding with dark people and there at the beginning of the sixties I'd cross Chelsea bridge, walk my children up by Cheyne Walk, sometimes waiting to watch a candle lighting. Gradually it became more real to me that I loved him, that we were active within a certain sacrifice. Both of us had been bare and destitute when we met. The two of us had warded off total calamity, total loss. 'Jamesy!' His picture swooned; he was like a ravaged corpse in my head

\footnotetext{
${ }^{30}$ Neid kujundeid pole palju, aga ka teksti laiali puistatult ilmnevad need väga teravalt: kõrged pilved mõjuvad groteskselt nagu Neitsi Maarja hiigelkuju kloostrihoone alkoovis, Mariat pinniv ülemõde on nagu robot Hispaania inkvisitsioonikohtus, protestimarssijate protest on nagu ohverdus.

${ }^{31}$ Oma esialgses tõlkes ei pööranud ma erikodeeringule tähelepanu, tõlkides resurrected keelendiga „uue elu sisse puhunud”.

${ }^{32}$ Kordub Ballinasloe ruumist tuntud laadamotiiv, samuti liikumine lapsevankriga, nüüd küll juba oma lapsega.
} 
and the area between us opened; in Chelsea library I began reading books by Russian authors. ${ }^{33}$ I began loving him again. A snatch of Glenn Miller fell across the faded memory of colours in the rain, lights of the October fair week in Ballinasloe, Ireland.

The world was exploding with young people - protests against nuclear bombs were daily reported - but in me the nuclear area of the town where I'd worked returned to me.

Jamesy and I had been the marchers. 'I like your face,' Jamesy once said to me. 'It looks like you could blow it away with a puff.' (Hogan 2013: 12) $)^{34}$

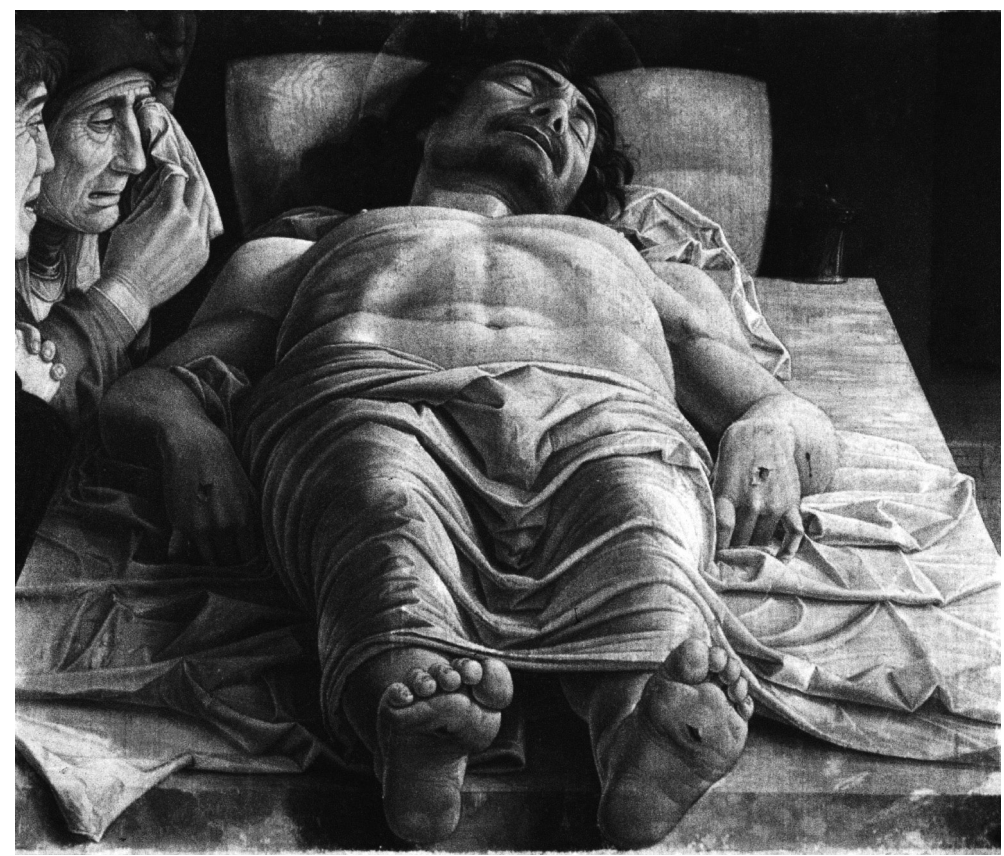

Pilt 4. Andrea Mantegna "Itk surnud Kristuse kohal" (ca 1480). (https://pinacotecabrera.org/en/ collezione-online/opere/the-dead-christ-and-three-mourners/ (25. VIII 2020))

\footnotetext{
${ }^{33}$ Raamatute hulgas, mis Jamesy oli Mariale laenanud, oli klassikalisi vene autorite teoseid ja muud väärtkirjandust.

34 '[---] aga vahetevahel, kui ma lapse vankriga Battersea lõbustusparki sõidutasin, tuli mulle meelde Jamesy; too tema isevärki üle näo langev juuksekahlakas. Kus ta oli? Kus oli see valu ja see nägu ja see tundlik meel? Londonis uputas mustanahalistest inimestest ja seal, kuuekümnendate alul, läksin ma sageli jalgsi üle Chelsea silla, kõndisin koos lastega Cheyne Walk’i mööda üles, jäädes mõnikord ootama, kuni kusagil küünal põlema pandi. Mulle hakkas üha rohkem teadvusse jõudma, et ma armastasin teda, et me olime kahekesi koos millelegi ohvriks toodud. Olime mõlemad olnud paljad ja üksikud, kui me kokku saime. Olime kahekesi eemale tõrjunud täieliku hävingu, täieliku kaose. „Jamesy!” Tema senine pilt varises kokku; see oli veel kui räsitud laip mu peas ja meie vahel olev ruum avanes; ma hakkasin Chelsea raamatukogus lugema vene autoreid. Ma hakkasin teda uuesti armastama. Killuke Glenn Millerit langes hägusale mälestusele vihmas sillerdavatest värvidest, oktoobrilaada tuledest Ballinasloes, Iirimaal. // Maailm lausa pakatas noortest inimestest - iga päev tuli teateid tuumapommivastastest protestidest -, aga minus ennistus too tuumaala linnas, kus ma siis töötasin. // Jamesy ja mina olimegi olnud need protestimarssijad, Jamesy ja mina olimegi see protest ise! „Mulle meeldib su nägu," oli Jamesy kord öelnud. „Näib, et selle saab ühe pahvakuga ära puhuda.”
} 
„Make love, not war” pole küll kusagil otse välja öeldud, aga on ikkagi selgesti aimatav. Mariale meenub tuumavastaste meeleavaldajate üle mõtiskledes nende „tuumaala” (nuclear area). Samuti kasutab Jamesy - nii meenub Mariale nüüd veidrat väljendit tema näo kirjeldamiseks: ilmselt on nägu nii õrnake, et selle võiks lihtsalt ära puhuda. Jamesy süütu blow away vihjab ühtlasi sellele, mida teevad pommid inimkehade või nägudega. Tekstipoeetiline tõlgendus osutab, et Maria ja Jamesy on oma n-ö plahvatuslikus armastuses olnud võrdväärsed tuumapommivastase hipipõlvkonnaga.

Ja ometi pole selline erikodeering ainuke võimalus. Kuidas mõista Jamesy piinatud keha kujundit Maria mälus? Muidugi võib siin olla samuti mingi seos tuumapommi ohvritega. Aga kristlikus võtmes võib see kujutada ka ristilt maha võetud Kristuse laipa (vt pilti 4). Võimalikku kristlikku kujundlikkust kohtame kohe esimeses lõigus, kus jõgi on pooleldi surilinaga kaetud (half-shrouded in fog [shroud 'surilina']).

Igal juhul avardub Maria mäluruum (the area between us opened 'meie vahel olev ruum avanes' (Hogan 2013: 13)) uute erikodeeringute toimel: vesternlik kodeering annab aluse ohverduskodeeringule kas kristlikus ${ }^{35}$ või tuumapommivastase liikumise võtmes, tegelikult võiks neist mõelda kui teineteist täiendavatest.

\section{Reaalne konkreetne ruum vs. abstraktne ideaalne ruum}

Lefebvre on õigusega juhtinud tähelepanu abstraktsele, sümbolilisele osale sotsiaalse ruumi representatsioonis. Ruumiteadvuses võib esineda nii reaalne kui ka ideaalne komponent, kusjuures viimane saab avalduda eri viisil. Nii lõpeb füüsiline Euroopa Uuralitega, poliitiliselt ideaalne Euroopa aga Narva jõega. Muidugi võib piir olla takistusena ka füüsiline, mitte ainult institutsionaalselt ideeline. Maria mäletatud ja kirjeldatud ruumid on konkreetsed ja reaalsed, aga nendega põimuvad ka kujutluslikud ja fantastilised, ideaalsed unelmateruumid. ${ }^{36}$ Marial oli jõekaldal, kus nad hiljem Jamesyga kohtusid, oma unistamise paik.

There'd been one particular tree there, open like a complaint, where I spent a lot of time surveying the river and the reeds, waiting for pirates or for some beautiful lady straight out of a Veronica Lake movie to come sailing up the river. (Hogan 2013: 9) $)^{37}$

\footnotetext{
${ }^{35}$ Selles võtmes oleks tegemist Kristuse ja Maria Magdaleena arhetüüpse looga.

${ }^{36}$ Foucault näitab, kuidas utoopia seguneb sageli heterotoopiaga, tuues näite peeglist, milles on esindatud ühtaegu nii peegli loodud virtuaalne ruum kui ka peegli enda reaalsus. Samal kombel on Maria unistamispaik reaalne, kujutluslik ruum aga virtuaalne. Kujutluslik ruum võimaldab ebameeldiva reaalse ruumi asemel luua „reaalsema” ruumi. Pealegi on kujutlemine ise reaalne ja ruum, milles kujutlemine aset leiab, funktsioneerib heterotoopiana.

37 'Jõe ääres kasvas üks eriline puu, võra ülespoole avanev otsekui kaebus, mille kõrval ma sagedasti istusin ja jõge ning pilliroogu vaatlesin, oodates kas piraate või mõnd kaunist leedit mõnest Veronica Lake’i filmist paadiga ülesvoolu seilavat'’
} 
Teisalt avaldub ideaalne ruum ka abstraktse, lausa geomeetrilise ringina, mis pole sellisena küll kunagi päris täpselt esitatud..$^{38}$ Ma viitasin eespool tôlkeprobleemile seoses Jamesy kodumajaga, mis asus linnakese välisringil või perimeetril, ja meie abstraktsele ja ideaalsele ruumitajule, sest oleme harjunud tajuma linnaruumi keskpunkti ja perifeeria vastandusena. Aga teatud ideaalruumiline teadvus ühendab ka meie sotsiaalseid suhteid ja ühiseid tegevusi. Me räägime perekonna ring i st, noorte naturalistide ringist, näiteringist jne. Mis asetub ringi keskpunkti koostöö, sõprus, armastus, tõde? Polegi nii oluline, mis see just igal konkreetsel juhul on, aga kindlasti on see miski, millest kõik on võrdsetel kaugustel, justkui Dante armastajad Armastusest. Maria ja Jamesy loos kujuneb nende "armastuse ruumi” (ringi) sümboolseks keskpunktiks sild, mis näib Maria jaoks sümboliseerivat ka nende vaimset sidet.

He began lending me books and under the pillow I'd read Zola's Nana or a novel by Marie Corelli, or maybe poetry by Tennyson. There was always a moon that summer - or a very red sunset. Yet I rarely met him, just saw him. Our relationship was blindly educational, little else. There at the bridge, a central point, beside which both of us paused, at different times, peripherally. There was me, the pram, and he in a shirt that hung like a king's cloak, or on cold days - as such there often were - in a jumper which made him look like a polar bear. (Hogan 2013: 9) $)^{39}$

Romantiseeritud loodusliku ruumi mälestusele lisandub ideaalse ruumi - silla mälestus. Sild oli noorte armastajate kokkusaamiskoht (vähemalt Maria jaoks) isegi siis, kui nad ei kohtunud, vaid jäid selle ümber - ka teise kohalolekuta - seisma p er if e e r s elt, otsekui ringjoonel.

Ma arvan, et novelli ruumipoeetika suunab ringi kujundit silmas pidades käsitlema ka seda kogemust, mis Marial tekib seoses tuumapommivastaste marssijatega. Tuumapommi plahvatus on teadupärast ringjas. Samuti meenub Mariale seoses marssijate ringiga (kelle ideaalide keskpunktis on „make love, not war”) ka nende enda armastuse ring, nende kunagine tuumaala Ballinasloes. ${ }^{40}$

\footnotetext{
${ }^{38}$ Olen võrrelnud Hogani armastuse ringi Dante „Uue elu” Armastuse ringiga, mille keskpunkt Amor ütleb Dantele: „Mina olen nagu ringi keskpunkt, millest kõik ringjoone osad on samavõrd kaugel; [aga sinuga see nii ei ole]" (vt Ploom 2019).

${ }_{39}$ 'Ta hakkas mulle raamatuid laenama ja ma lugesin padja alt Zola „Nanad”, Maria Corelli romaane, mõnikord ka Tennysoni luulet. Tol suvel näis kuu alati paistvat ja päikeseloojangud olid erepunased. Ometi kohtusin ma temaga harva, ainult nägin teda. Meie suhe oli puhthariduslik, ei enamat. Sealsamas sillal, keskses punktis, mille ümber me mõlemad eri aegadel peatusime, justkui ringjoonel. Seal olin mina, oli lapsevanker ja tema oma särgis, mis lotendas nagu kuninglik kuub, või siis külma ilmaga - aga seda tuli sageli ette - džempris, milles ta nägi välja nagu jääkaru.'

${ }^{40}$ Hogani tekstis on the nuclear area of the town where I'd worked returned to me 'mulle tuli uuesti meelde tuumaala linnas, milles ma olin töötanud'. Autori (ala)teadvuse toime aspektist, mis pole küll selle kirjutise fookuses, tasub mainida, et Maria töötas lisaks Ballinasloele ka Athlone’is. Lõuna-Aafrikas asub nimelt üks teine Athlone, mille koletuslik tuumajaam on nüüdseks demonteeritud, ent mis oli kindlasti täies töökorras sel ajal, kui Hogan oma novelli kirjutas.
} 


\section{Integreeritud heterotoopiline ruumiteadvus}

Ruumiuurijal, ka kunstiteose ruumipoeetika uurijal, on vaja läheneda oma uurimisobjektile nii analüutiliselt kui ka sünteetiliselt, sest eri ruumid justkui sulanduvad. Ometi teadvustame ruumilisi erinevusi. Me avastame ruumi seda kehaliselt tajudes. Merleau-Ponty järgi võiks isegi öelda, et me loome ruumi, tajudes oma kehaga teisi kehasid. Samal ajal me liigume tegevuslikult sotsiaalselt representeeritud ruumides, milles on oma heterotoopiad, mida me vähemal või rohkemal määral sellistena teadvustame. Lefebvre’i ja Foucault' järgi saame eristada Maria tegevuste kaudu tajutud ruume: jalutuskäigud kloostri orbudekodu nunnadega ja eraldatus n-ö korralikest lastest; Maria suletud töötsoonid; sotsiaalselt erinev tegevus muidu justkui ühises ruumis (nt laadaplats, eri klassi vagunid rongis). Tajutud seesmised ruumid põimuvad seega linlikult kontseptualiseeritud väliste ruumidega, mida ikkagi tajutakse ka seesmiste ruumidena (keha ja objektide vahelise liikumise tõttu) ning mis just seetõttu ilmnevad Hogani novellis küllaltki katkendlikult. Nii tajutud kui ka kontseptualiseeritud ruum ühenduvad Maria enda representeeritud ja erikodeeringuga (ümber)mõtestatud ruumidega.

Seega põimuvad (seesmine) füüsiline ruumitaju ja (välised) sotsiokultuurilised koodid. Representeeritud ruumid, mis ühendavad kloostriruume, raamatuid, filme ja muud, vormides noore Maria füüsilisi tajumusi, ilmuvad kirjutava Maria mälestustes assotsiatiivselt.

There were high clouds against a low sky that winter and the grotesque shapes of the Virgin in the alcove of the church, but against that monstrosity the romance was complete I reckon, an occasional mad mood, "Lili Marlene" on radio - memories of a war that had only grazed childhood - a peacock feather on an Ascendancy-type lady's hat.(Hogan 2013: 10) ${ }^{41}$

Tekstilõigus on ühendatud madal talvetaevas, Jumalaema kuju hiigelvormid, punase täiskuuaja pöörane ruum koos „Lili Marlene’i” (sõjaaja lapsepõlveruumi mälestus) ja iiri (inglisemeelse) protestantliku daami kübarasulg. ${ }^{42}$ (Kirjutava) Maria integreeritud ja samal ajal ikkagi heterotoopiline teadvus on hämmastavalt kirju ja trafaretne: kunstilises tekstis on teatud valikud eksplitsiitselt või implitsiitselt seostatud (võib imetleda kirjutava Maria, teisisõnu Hogani erikodeeringute paljusust), tavateadvus jääb kaootilisemaks.

Sellist terviklikkust ning ühtaegu eristavust kohtab tegelikult novelli igas lõigus. Iga tekstilõik on oma (ruumi)poeetikalt peaaegu nagu kogu tekst, mis avab end tõlgenduseks tekstilt teosele ja tagasi liikudes.

\footnotetext{
$\overline{41}$ 'Tol talvel olid madalas taevas kõrged pilved ja Neitsi Maarja hiigelkuju kiriku alkoovis, aga selle mõõdutuse taustal tundus mulle meie romaan igati terviklik - mõni hullumeelne täiskuuaeg, „Lili Marlene” raadios - mälestused sõjast, mis oli mu lapsepõlve ainult riivanud -, jaanalinnusulg protestantliku daami kübaral.'

${ }^{42}$ Siingi tuleb esile uute sotsiaalsete, kultuuriliste ja poliitiliste heterotoopiate võimalus, mida küll tekstis edasi ei arendata.
} 
Always our meetings had occurred when I brushed past Jamesy with the pram. This was our first night out, seeing that Christmas was coming and that bells were tinkling on radio; we'd decided we'd be bold. I'sneak out at eight o'clock, having pretended to go to bed. What really enticed me to ask Jamesy to bring me to the pictures was the fact that he was wearing a new Aran sweater and that I heard the film was partly set in Marrakesh, a place that had haunted me ever since I had read a book about where a heroine and two heroes met their fatal end in the city. (Hogan 2013: 10) ${ }^{43}$

Kirjutava Maria teadvuses põimuvad noore Maria situatiivne ruumitaju, tema liikumine Jamesy turvalise ja pehme Arani villast sviitri poole (nägime riietuse tajumise tähtsust mujalgi tekstilõikudes), kloostri tavakohase jõuluruumi rikkumine kinosaali seiklusliku ruumiga, milles tema enda avantüür põimub raamatus kujutatud Marrakechi ohtliku ruumiga.

\section{Fenomenoloogilise tõlke poole}

Ideaalne tõlkeprotsess peaks hõlmama analüütilist ja sünteetilist faasi. Analüütilises faasis tuleks lasta avaneda teksti tajumuslikul ja väljenduslikul kontekstil, eriti aga ruumitaju representatsiooni protsessis saadud kultuurilistel erikodeeringutel (sotsiaalse ruumi heterotoopia ei tekita nii palju probleeme) ja liikuda sünteetilises, niiöelda päristõlke faasis, lineaarse teksti ja teose kui tervikteksti koostoimes.

Olen veendunud vajaduses kultuurilised erikodeeringud selgemalt esile tuua. See puudutab näiteks eespool analüüsitud „kurikaelanaeratust” ja kleitide „surnuist üles äratamist”. Jamesyt „embav mantel” oleks siiski liiast, ${ }^{44}$ samuti surilinana tajutud udu, sest udu pole tekstis sellisena esil.

Samuti pole eksplitseeritud novelli (lõpulause) mõte „Ma liigun tõe poole” ('I touch upon truth'), nii et tõlkimisel peaks ikkagi piirduma keelendiga „Ma puudutan tõde”.

\footnotetext{
$\overline{43}$ 'Meie kohtumised olid seni aset leidnud nii, et mina põrutasin vankriga temast kusagil mööda. See oli meie esimene õhtune kohting, sest jõulud olid kohe tulemas ja raadiost lasti kellade helinat; niisiis me otsustasime, et tuleb tegutseda. Ma hiilisin kell kaheksa kaupmehe majast välja, olles enne teeselnud voodisse minekut. Mis mind tegelikult ärgitas lasta end Jamesyl kinno viia oli see, et tal oli seljas uus Arani kampsun ja et filmi tegevus toimus osaliselt Marrakechis kohas, mis kummitas mind sest ajast saadik, kui lugesin üht raamatut, milles kangelanna ja kaks kangelast tollessamas linnas oma kurva lõpu leiavad.'

${ }^{44}$ Äärmisel juhul võiks tõlkida nii: „Tema pikka kogu näis embavat mantel, mis oli tema jaoks liialt suur", aga see poleks enam algtekstiga vastavuses. Gideon Toury (2000: 201) on osutanud tõlkimise kahele vastandlikule poolusele: vastavusele (adequacy) algteksti suhtes ja vastuvõetavusele (acceptability) tulemkultuuri suhtes.
} 


\section{Kokkuvõte}

Maria tajud - nägemistaju (kujud, värvid), puute-, lõhna-, maitse- ja kuulmistaju, samuti liikumuslikkus kui taju eriline omadus - on seotud tema individuaalse, nii konkreetse kui ka kujutlusliku ruumitaju ja -teadvusega:

Jamesy now was lost, looking out of a window I'd think of him but like the music of Glenn Miller he was past. His hair, his face, his madness, I'd hardly touched, merely fondled like a floating ballerina.

It had been a mute performance - like a circus clown. There'd been something I wanted of Jamesy which I'd never reached; I couldn't put words or emotions to it but now from a desk in London, staring into a Battersea dawn, I see it was a womanly feeling. I wanted love. (Hogan 2013: 11) ${ }^{45}$

Londoni konkreetsesse igapäevaruumi lõikub kunagi tajutud ja samal ajal ikkagi seni, enne kirjutamist, ebaadekvaatselt (või vähemasti teistmoodi ${ }^{46}$ ) kontseptualiseeritud ruum, mis tahab uuesti läbielamist ja uut tõlgendamist, pärast mida Maria võib rahunenult tõdeda: „I touch upon truth” - „Ma [peaaegu] puudutan tõde”.

Kogetud ruumi keelelisel representeerimisel lähtub Maria oma kultuurilisest kogemusest, nii nagu kõik inimesed, ehkki kunstilisele tekstile omaselt ilmselt siiski fokusseeritumalt. Jamesylt laenatud raamatute hulgas leiduvatest Nižinski päevikutest või filmides nähtud balletistseenidest ammutatud kujutlusliku ruumi kogemuse ajel võrdleb Maria oma suhet noormehega baleriini põgusa puudutusega hõljuval liikumisel. Kogu nende suhe on olnud otsekui tumm tsirkuseetendus: just nii kutsub seda tõlgendama novelli alguse sõnatu hüvastijätustseen ja teineteist välistav sõit sama rongi eri klassi vagunites, milles sotsiaalsed heterotoopiad nii teravalt avalduvad.

Üks asi jääb siiski närima. Mis oleks, kui lugu oleks esitatud Jamesy ruumitaju ja representatsiooni kaudu? Võib-olla oleks lahkumisstseen raudteejaamas siis vastupidiselt tajutud ja representeeritud. Võib-olla ei julgenud Maria oma seisusevahe ja viletsa kleidi tõttu ise poisile ligineda? Me ei saa selle kohta siiski midagi täpsemat öelda, nii et piirdugem Maria ruumidega.

\footnotetext{
45 'Jamesy oli nüüd minevik; vaadates aknast välja, ei mõelnud ma temast rohkem kui Glenn Milleri muusikast, mis oli ka minevik. Tema juuksed, tema nägu, tema sõgedus, mida ma olin vaevu puudutanud, vaid põgusalt paitanud nagu temast mööda libisev baleriin. See oli olnud tumm etendus - nagu tsirkuseklouni pantomiim. Jamesys oli midagi, mida ma olin tahtnud, aga milleni ma polnud kunagi küündinud; ma ei osanud seda sõnadesse panna ega emotsioonina kirjeldada, aga nüüd siin, oma Londoni kirjutuslaua taga, kui vaatan Battersea koidikut enda ees, saan ma aru, et see oli naiselik tunne. Ma tahtsin armastust.'

${ }^{46}$ Uus representatsioon pole suuremale selgusele vaatamata tingimata õigem.
} 


\section{VEEBIVARAD}

Great Western Movies. The Best of Wild West Film and History. http://thegreatwesternmovies.com

Pinacoteca di Brera. https://pinacotecabrera.org

\section{KIRJANDUS}

Eco, Umberto 1979. A Theory of Semiotics. Bloomington: Indiana University Press.

Eco, Umberto 2008 [1975]. Trattato di semiotica generale. Milano: Bompiani.

Foucault, Michel 1984 [1967]. Of Other Spaces: Utopias and Heterotopias. Tlk Jay Miskowiec. http://web.mit.edu/allanmc/www/foucault1.pdf (4. II 2020).

Hogan, Desmond 2013. The last time. - D. Hogan, The House of Mourning and Other Stories. Champaign-London-Dublin: Dalkey Archive Press, lk 7-13.

Merleau-Ponty, Maurice 2002 [1945]. Phenomenology of Perception. Tlk Colin Smith. London-New York: Routledge.

Merleau-Ponty, Maurice 2019 [1945]. Taju fenomenoloogia. Tlk Mirjam Lepikult. (Avatud Eesti raamat.) Tartu: Ilmamaa.

Lefebvre, Henri 1991 [1974]. The Production of Space. Translated by Donald NicholsonSmith. Oxford, UK-Cambridge, US: Blackwell.

Lotman, Juri 1991 [1981]. Retoorika. Tlk Inta Soms - J. Lotman, Kultuurisemiootika. Tekstkirjandus-kultuur. Tallinn: Olion, 1k 217-246.

Ploom, Ülar 2019. On the poetic of the double point and circle in Dante's Paradiso 30 and in Desmond Hogan's short story „The Last Time”. - Studia Metrica et Poetica, kd 6, nr 1, lk 79-93.

Torop, Peeter 1995. Total'nyj perevod. Tartu: Izdatel'stvo Tartuskogo universiteta. [Пеэтер Тороп, Тотальный перевод. Тарту: Издательство Тартуского университета.]

Toury, Gideon 2000. The nature and role of norms in translation. - The Translation Studies Reader. Toim Lawrence Venuti. London-New York: Routledge, lk 198-211.

Ülar Ploom (snd 1955), PhD, Tallinna Ülikooli humanitaarteaduste instituudi dotsent, (Narva mnt 29, 10120 Tallinn), ylar@tlu.ee 


\title{
On the perception of space, its linguistic and cultural coding and poetics of representation in Desmond Hogan's short story "The Last Time"
}

\author{
Keywords: phenomenology of space perception, social space, linguistic and cultural \\ representation of space, extracoding of real and ideal spaces, phenomenology of \\ translation
}

The present article studies the perception of space in "The Last Time" (a short story written by Desmond Hogan, first published in 1979) by Maria (a former orphan in the nunnery of Ballinasloe, a small town in western Ireland, close after WW II), who makes an attempt in her first person narrative to represent and understand, twenty years later, the circumstances and the emotions of her love for a young man from a socially high-ranking family, which probably failed because of the social and cultural conventions of their time. The article focuses Maria's highly individual space perception and its linguistic representation based on her linguistic and cultural habits. Maria's spaces, which integrate both real and ideal spaces, are analysed with reference basically to Maurice Merleau-Ponty's "Phenomenology of Perception", Henri Lefebvre's "The Production of Space" and Umberto Eco's ideas on extracoding exposed in his "Theory of Semiotics". The article also deals with the difficulties that translators meet when translating this short story. It appears that most translation problems are connected with Maria's specific cultural overcodings in an attempt to represent her space perception. The author of the article analyses some examples of his previous translation and offers some new solutions in the section entitled "Towards phenomenological translation".

Ülar Ploom (b. 1955), PhD, Tallinn University, School of Humanities, Associate Professor of Italian Literature (Narva mnt 29, 10120 Tallinn), ylar@tlu.ee 